\title{
Research on Brand Management of Domestic Mid-End Chain Hotels Based on Customer Perceived Quality
}

\author{
Xiaoying Dong \\ Xi’an Fanyi University, Shaanxi Province, China,710105
}

Keywords: Customer perceived quality, Brand management, Mid-end chain hotels

\begin{abstract}
With the economic development, the frequency in tourism, business meetings, academic exchanges and other activities has been increased. This makes the management of the mid-end chain hotels become an industry development trend. Under the influence of Internet information, the hotel brand effect based on customer perceived quality has great influence on the operation performance of the mid-end chain hotels. Therefore, this paper will explore the internal relationship between the customer perceived quality and brand management in the mid-end chain hotels management. It will help achieve the brand management of the mid-end chain hotels based on the customer perceived quality, and discuss the application strategy of the brand value in order to enhance enterprise reputation.
\end{abstract}

\section{Introduction}

The mid-end chain hotels provide the comprehensive services such as catering, accommodation, relaxation and entertainment to the public. It plays an important role in China's economic development. With the improvement of people's living standard, the demand for the consumption quality is increasing, and the recognition about the word of mouth and brand is becoming more and more important. The mid-end chain hotels are different from the high-end hotels. They service the ordinary working class customers with large population and the centered consumption level. These customers have more rational consumption in this knowledge economic are. Especially under the fast information development, the visibility, reputation, service quality and environment of the hotels influence the customer satisfaction and loyalty. Therefore, it is the best breach to search the brand management of the mid-end chain hotels based on the customer perceived quality in China.

\section{Overview of the customer perceived quality}

\subsection{Definition of the customer perceived quality}

Customer perceived quality is one comprehensive judgment of service quality and mental expectation. If the customers have gentle mental expectation about the actual product or service, even higher mental expectation, there will have high customer perceived quality. Otherwise, if the customers' mental expectation below the actual product or service, there will have low customer perceived quality. Customer perceived quality is a subjective representation based on customer perception of the appropriate service and ideal service. Different customers have various perceived quality of the product and service. The customer perceived quality need to include different dimensions such as personnel service, facility environment, service process, service response, product quality, product effect and so on.

\subsection{Evaluation system of the customer perceived quality}

If we quantify the dimension and factors of the customer perceived quality, build the evaluation system, we will find the distance between the customer expectation and actual service quality. This is one effective way to improve the product or service of the modern enterprise management. We take the customer perceived quality as a whole, which include customer expectation and the actual experience quality. The customer expectation come from the marketing communication, customer 
requirement, cooperate image and public praise. The customer experience quality is the comprehensive image of the enterprise, which include technical service quality and functional service quality.

The customer expected service psychology come from the personal needs, past experience, social reputation and brand. For the distance between customer expected service and the actual service, we can obtain customer expectation form service transformation and service communication. The customer perception will be transformed into the standard of service quality management. Through various methods, we can reach the customer's expected service, so that it can choose consumption.

\subsection{Measuring method of the customer perceived quality}

The existing measuring method is SERVQUAL model and scale from PZB. This method is a perceptive quality measurement method for the perceptual service and expectation service composed of 5 dimension and 22 test factors, which include reliability, responsiveness, guarantee, empathy and physical dimension. Reliability factors include: the completion of the enterprise's commitment, the ability of the enterprise to solve customer problems, etc. The responsiveness factors include the accuracy of service time and enterprise service initiative, etc. The guarantee means the enterprise obtains the trust of employees and customers, and the employees can gain the recognition of customers. Empathy means should not be expected to give customers special services. The tangible is to ensure the enterprise in the equipment, image, service and other aspects are advanced.

\section{Brand connotation and value}

\subsection{Brand definition}

Brand is a product quality or service image consisting of name, symbol, pattern and term. Brand has uniqueness and specificity, it is the differentiation feature of similar products and services. With the establishment and maintenance of the enterprise brand, the brand has become more and more widely recognized by the society, and it has an intangible value. It can provide customers with the guidance of perception, and become the business card of reputation, product quality, service quality and reliability.

\subsection{Brand value}

Brand value is made up of brand image, brand awareness and brand loyalty. It comes from the multi-dimensional combination, which has the brand characteristics, the brand personality and the overall image of the enterprise. Brand image originates from consumers' understanding of brand names and patterns, and is integrated into the enterprise value and the drive of consumers' guidance and belief in consumption. Brand awareness refers to the popularity of the brand. Its index is the number of consumers and consumer cognition. Brand awareness also includes consumers' brands feelings, brand culture, brand experience and brand reputation. The brand knowledge comes from the brand quality performance and service guarantee, on the other hand, it comes from the psychology of consumer demand. Brand loyalty is to form consumers' consumption preference through brand. No matter how the external environment changes, brand consumption has become a belief.

\subsection{Evaluation system of the brand value}

The evaluation of brand value comes from many aspects. It mainly includes cost analysis, brand contribution analysis and brand equity analysis. Cost analysis is the social average investment rate obtained through commodity cost and operating cost, which leads to the value of brand operation cost. Brand contribution analysis is to obtain product premium and consumer preference through consumer survey to get the brand current revenue contribution. By using the judgment method, we can predict the discount rate of future earnings, and then discount the future earnings of the brand. In the end, the brand's comprehensive value will be acquired by the brand operation cost value, 
brand current income contribution, and the discounted future earnings of the brand.

\section{Brand management of mid-end chain hotels based on customer perceived quality}

\subsection{Brand management process of the chain hotels based on customer perceived quality}

With the continuous deepening development of market-oriented economy, the chain hotel service operation has become the main mode of competition in the industry with the unified specification and standard. High quality service is the key of hotel enterprise brand building. Especially in the Internet era, the purpose of chain hotel brand establishment is to cultivate customer loyalty and create added value for the hotel. Customer perception quality is the main body of chain hotel brand image. Through various factors to improve the customer's good evaluation of the hotel is the core center to maintain and promote the brand. At the same time, we can obtain customer perceived quality improvement service level and targeted brand promotion from customer feedback. Then we can build customer perceived quality and brand management process based on customer perceived quality expectation. Figure 1 has the details.

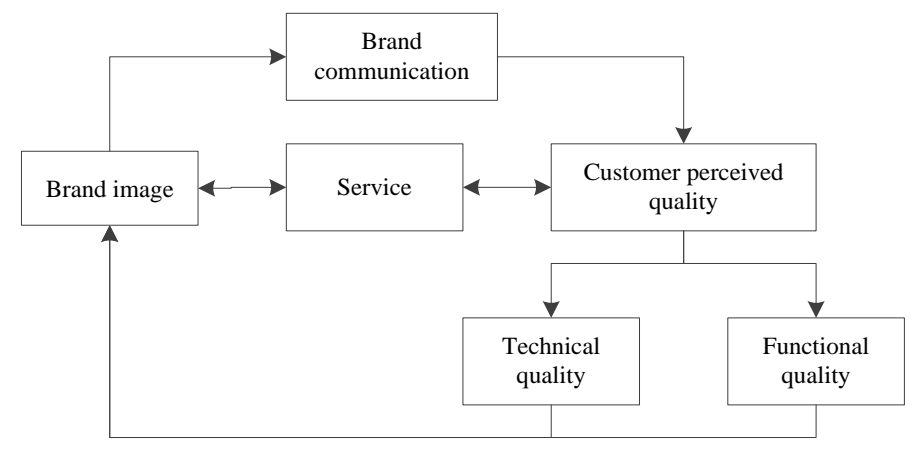

Figure 1. Brand management process based on customer perceived quality

We can build brand image through technical service and functional service, communicate with customers through the brand and establish the brand awareness. Customers gain perceived quality through brand and hotel services. The feedback technical quality information and functional quality information will be submitted to brand management. After service optimization, brand communication is carried out to give customers new perceived quality. Therefore, the circular relationship establishment can continuously improve the hotel's service level, increase the brand management ability of the hotel, and also continuously satisfy the customers' perceived quality demands, gain customer recognition and trust in the brand.

\subsection{Relationship between customers perceived quality and brand management of chain hotel}

Connect perceived quality and brand value, we can build the research model based on 5 dimensions of the perceived quality and brans value system. Among them, the customer perceived quality as the independent variable, which include the following details. Tangible variable contents are such as: environment, lighting, decoration atmosphere, attendant personnel makeup, service personnel appearance, etc. Reliability variable contents are such as sound insulation effect, temperature control, cleaning, room reservation service, commitment service, etc. The responsive variables contents are such as: check out, customer's consultation answer efficiency, delivery service, handling emergency failure rate, etc. Contents of guaranteed variables are such as service attitude, service etiquette, job responsibilities, communication skills, problem solving ability, etc. The contents of the transference variable are: employee remembers the customer's name, records the customer's personalized consumption behavior, and exceeds the customer's expected service. The brand value is used as the dependent variable to construct the evaluation index. The contents of brand image variables include: hotel appearance, hotel interior decoration, hotel history, hotel brand difference cognition, etc. Brand awareness variables include: customers have heard of it, customers have been aware of it, and customers have checked in. The contents of brand loyalty variables 
include: customer preferred hotel, customer repeat check-in, customer check-in satisfaction, and customer voluntary publicity.

The survey method was used to obtain the indicators of customers' perceived quality variables. Grade the variables with 5 points of very poor, poor, general, good, and very good. On the basis of reliability test consistency, we can confirm the relationship between the five dimensions of customer perceived quality and brand value. The results show that there is a positive correlation among the content of the results, the reliability, the transference and the content of the guaranteed variables. The content of responsive variables is negatively correlated with brand image. Assurance and reliability variables are positively correlated with brand awareness. The content of physical, empathic and responsive variables is negatively correlated with brand awareness. Assurance, reliability, responsiveness, and transference variables are positively correlated with brand loyalty. Tangible variable content is negatively correlated with brand loyalty.

\subsection{Brand management strategy of chain hotels based on the customer perceived quality}

After understanding the relationship between customer perceived quality and brand value, the hotel brand management is more targeted and effective according to the actual situation of domestic mid-end chain hotels. Based on the customer perceived quality, this article provides the strategy of strengthening the management of brand awareness, build customer trust mechanism, develop the level of hotel services, intangible service marketing, hotel service efficiency, increase the added value of the hotel, and expand brand awareness of brand management strategy.

Establish the awareness of brand value and take brand image, brand awareness, brand loyalty as the core content of brand management. Provide good service facilities and supporting services, cultivate the common courtesy and service habits of employees. Create intangible value through tangible service and improve hotel's service level. Pay attention to humanized design, continuous innovation, reflect the unique advantages of the hotel. Service efficiency is the key point to influence and brand loyalty. In the chain hotels service, we should establish standardized and uniform service standards, and conduct unified management of each branch. Moreover, it is also important to optimize service flow, establish quick response service management mechanism to solve customers' thorny problems. In today's hotel chain, we should not only meet the basic needs of customers, but also guide the consumption. We need to maintain the loyalty of customers' hotel consumption. First of all, we should pay attention to the customers' individual perception quality expectation and meet the personalized and flexible service demands of customers. We can provide the super business service and bring the unexpected surprise to the customer through the service details. Brand awareness is positively related to customer brand loyalty, expanding the brand awareness helps to consolidate the value of the brand in the customer's mind.

\section{Conclusions}

The research of this article provides the practical management strategy to the mid-end chain hotels in China. This method is obtained from the customer perceived quality with good effectiveness during the practical application. With the content of customer perception diversifying, customers' perception factor should be constantly integrated in the implementation of hotel brand management. Innovative development provides customers with more than expected service, forming a benign word-of-mouth delivery channel, highlighting the brand value of the hotel.

\section{Acknowledgements}

Project: The paper is the research findings of CCPIT Commercial Sub-council in 2017:" Research on Brand Management of Domestic Middle hotel chains Based on MBI” (Grant No.: FWYPPKT-1719) 


\section{References}

[1] Sun Dongmei, Zhang Chao, Influence of Hotel Brand Name on Consumer Quality Perception and Purchase Intention [J]. Tourism Overview, 2015(3):46-46

[2] Zhang Yang. Research on the Improvement of Hotel Service Quality Based on Customer Perception [J]. Journal of Chifeng University (Natural Science Edition), 2016, 32(7):166-167

[3] Qian Wei, Research on the Brand Construction of Local Hotels Based on Customer Perception -- taking Hefei Peace International Hotel in Anhui as an Example [J]. Tourism Overview, 2015 (2): 153-155.

[4] Yi Qidong, Research on Customer Perception in Service Quality of hotel Industry in China [J]. Executive, 2015(1):34-35

[5] Gong Hui, Sun Pai, Analysis on the Influencing Factors of Customer Loyalty about Overseas High-star Brand hotels [J]. Economic \& Trade, 2017(4):27-27

[6] Wang Miao, Wang Shuang, Brief Discussion on How to Improve the Personalized Service Level of International Brand Hotels. Foreign Economic Relations \& Trade, 2014, 12, p.127-128

[7] Xia Wenting, Hu Zhijian. Research on Social Media Marketing of Branded Hotels of International and Chain-Comparative Study with Independent Hotels, Jiangsu Commercial Forum, 2015, 4, p.3-9 